\title{
A Comparison of the Effectiveness of Ethnomathematics and Traditional Lecture Approaches in Teaching Consumer Arithmetic: Learners' Achievement and Teachers' Views
}

\author{
Gladys Sunzuma ${ }^{1 \star}$, Nicholas Zezekwa ${ }^{1}$, Isaac Gwizangwe ${ }^{1}$, Gracious Zinyeka ${ }^{1}$
}

\begin{abstract}
${ }^{1}$ Bindura University of Science Education, ZIMBABWE
\end{abstract}
*Corresponding Author: gsunzuma@gmail.com

Citation: Sunzuma, G., Zezekwa, N., Gwizangwe, I., \& Zinyeka, G. (2021). A Comparison of the Effectiveness of Ethnomathematics and Traditional Lecture Approaches in Teaching Consumer Arithmetic: Learners' Achievement and Teachers' Views. Pedagogical Research, 6(4), em0103. https://doi.org/10.29333/pr/11215

\section{ARTICLE INFO}

Received: 11 May 2021

Accepted: 25 Aug. 2021

\begin{abstract}
Past studies revealed that the integration of ethnomathematics approaches is of great importance in the teaching and learning of mathematics as it is believed to improve learners' understanding and achievement in mathematics. Cognisant of the benefits of using ethnomathematics approaches in teaching and learning mathematics, the Zimbabwean school syllabus recommends the adoption and integration of ethnomathematics approaches to improve the learners' performance. The purpose of this mixed-method study was to determine the comparative effectiveness of ethnomathematics approaches and the traditional lecture approaches as well as teachers' views on the use of ethnomathematics approaches. The study sample comprised 90 learners and two teachers from one secondary school in Bindura district in Zimbabwe. Two instruments, a test and interviews were used for data collection. The participating teachers taught the concepts of consumer arithmetic for four weeks. Findings of the study showed that learners taught using an ethnomathematics approach achieved significantly higher in the test than those taught consumer arithmetic using the traditional approach. The study revealed that teachers appreciated the use of ethnomathematics approaches in the teaching of consumer arithmetic as their learners were motivated, actively involved and interested in learning the concepts. It was also reported that ethnomathematics approaches improve learners' understanding and retention of arithmetic concepts. The study, therefore, recommended training of the teachers on the use of the ethnomathematics approach in the teaching and learning of consumer arithmetic.
\end{abstract}

Keywords: ethnomathematics approach, traditional lecture approach, consumer arithmetic, achievement

\section{INTRODUCTION}

In Zimbabwe at the secondary school level, mathematics is a compulsory subject because of its usefulness in almost all economic activities. In Zimbabwe, the mathematics syllabus comprises several topics of which consumer arithmetic is one of them. Consumer arithmetic involves interpretation of data in real-life situations such as water and electricity bills, bank statements, mortgages, and information in the media; budgets including household, co-operative and state budgets; rates in form of foreign exchange and household rates (Zimbabwe School Examination Council (ZIMSEC), 2015). Consumer arithmetic including the calculation of salaries and wages, insurance premiums, simple interest discount, commission, depreciation, sales/income tax, hire purchase and bank accounts including savings and current accounts paying bills and taxes and currency conversion assist consumers in accurate completion of their everyday transactions.

Despite the fact that consumer arithmetic is one of the topics that is widely used in everyday life, consumer arithmetic questions proved to be difficult for the learners. For instance, the ZIMSEC (2016) examiners' report showed that questions on consumer arithmetic were poorly done, from as simple as failure to calculate the percentage profit and converting dollars to cents. This could mean that the topic of consumer arithmetic may contribute to the low pass rate in mathematics among other topics. The poor performance in consumer arithmetic questions may also mean that learners would not be able to connect their everyday life situations (ethnomathematics) to their classroom learning.

Numerous factors have contributed to the poor performance in mathematics in general and consumer arithmetic in particular (Mashingaidze, 2012). One of such factors is the teachers' use of inappropriate teaching approaches (Harbor-Peters, 2001; Mashingaidze, 2012). In Zimbabwe, Sunzuma and Maharaj (2019) blamed the poor performance in mathematics on the traditional approaches used by the teachers. One of the concerns of overreliance on traditional approaches to teaching mathematics is the 
superficial lack of basic mathematical philosophies which leads to rote-learning and low performance in mathematics as observed in Zimbabwe (Sunzuma et al., 2012).

Following an analysis of learners' poor performance in Zimbabwe, Chiwiye (2013) suggested that teaching should take into account that learners actively construct knowledge related to social and cultural settings. Similarly, the ZIMSEC mathematics syllabus recommends bridging the gap between the mathematics taught in schools and the learners' worlds, through using their everyday experiences, cultural backgrounds and the surrounding environment (ZIMSEC, 2015). This idea concurs with recommendations from various scholars that when learners become conscious of the connection between what they learn and their everyday experiences, they are likely to be motivated to learn mathematics, which could stimulate and sustain learners' interest as well as improving their performance (Madusise, 2015; Rosa \& Orey, 2013; Sunzuma \& Maharaj, 2019; Weldeana, 2016). The integration of ethnomathematics approaches into the teaching of mathematics has several benefits such as active participation of learners, practical oriented and application of acquired knowledge to real-life situations as well as enhancing learners' conceptual understanding (Sunzuma \& Maharaj, 2019; Weldeana, 2016).

According to Rosa (2011), ethnomathematics is all the forms of mathematics that vary as a consequence of being embedded in cultural activities. Everyday activities which included building houses, exchanging money, weighing products and calculating proportions for a recipe involving numbers, calculations and precise geometry patterns are all ethnomathematics (Weldeana, 2016; Umbara et al., 2021). Ethnomathematics is a cluster of ideas concerning the history of mathematics, the cultural roots of mathematics, implicit mathematics in everyday settings, and mathematics education (Weldeana, 2016).

In 2009, Orey and Rosa noted that ethnomathematics enables scholars to examine what and how we teach mathematics in the context of the school, culture and society. Culture and school mathematics are widely related (Weldeana, 2016). The teaching and learning of consumer arithmetic can be influenced by the learners' cultural, environmental backgrounds and experiences. To solve consumer arithmetic problems, learners need to understand more about the role of mathematics in a societal context (Rosa \& Orey, 2011).

\section{LITERATURE REVIEW}

\section{Theoretical Framework}

A social constructivist theoretical framework guided and shaped this study since it is apprehensive with what takes place in the classroom and the need to improve the consumer arithmetic understanding and application. As indicated by Ernest (1999) social constructivism is a theory of mathematics that perceives mathematics as a cultural creation. Similarly, Vygotsky (1978) cited in Woolfolk, (2010) referred to social constructivism as a movement where construction of knowledge is done by learners using their past information in addition to their cultural and background knowledge.

The prevailing view is that learners do not exist in solitude, but they exist and learn in cultural environments where learning is shared and understanding is created with others (Woolfolk, 2010). According to Vygotsky (1978) cited in Woolfolk, (2010) knowledge is actively created in social environments and that the development of such knowledge is cultural. The most important idea governing Vygotsky's (1978) social constructivist theory is the concept that learners acquire knowledge from the individuals who have more understanding and information especially teachers through interaction in an environment that is culturally based. Additionally, scholars who advocate for social constructivism believe that culture and environment are essential components in understanding and accepting what happens in society, and knowledge construction must be founded on this understanding (Kim, 2001). The consumer arithmetic aspects used in everyday life could be used in the teaching and learning of consumer arithmetic concepts in the classroom.

Ethnomathematics approaches build on the learners' prior knowledge and experiences, their background, and the role played by their environment concerning the content and method, according to D'Ambrosio (2001). Kurumeh (2004) defined the ethnomathematics approach as a teaching method that is used in explaining the reality of the link between the learners' cultural environment and experiences to the teaching of mathematics. It is an approach that is learner-centered and rooted in social constructivism because it recognizes the knowledge that the learners bring into the classroom (Mogari, 2014). Social constructivism and the ethnomathematics approach share common views regarding the teaching of mathematics. Firstly, mathematical knowledge such as consumer arithmetic knowledge is socially constructed by the learner through social interactions with the environment. Secondly, the learning process occurs in realistic and contextualized daily activities that provide germane contextual meaning to the concepts learned in the classroom. The approach is practically oriented (D'Ambrosio, 2001 cited in Sunzuma \& Maharaj, 2020); it employs the rich cultural activities and experiences from the learners' environment and day-to-day experiences, such as everyday calculations on electricity and water bills.

\section{Integration of Ethnomathematics Approaches into the Teaching and Learning of Mathematics}

Most of the studies that advocate for the integration of ethnomathematics approaches into the mathematics curriculum are envisioned to make mathematics meaningful and relevant for the learners as well as promoting the overall quality of mathematics (Madusise, 2010; Rosa \& Orey, 2011). According to Rosa and Orey (2011) ethnomathematics approaches bring the out-of-school mathematics that is practiced in real-life situations into the classroom, thereby improving the understanding of mathematics concepts. Ethnomathematics approaches encourage connecting mathematics to the real world through authentic problems that enhance learners' conceptual understanding of the mathematics concepts.

Torress-Velasquez and Lobo (2004) cited in Rosa and Orey (2011) proposed that teachers should contextualize mathematics learning by relating mathematical content to learners' culture and their real-life experiences. This can be achieved by grounding 
mathematics instruction in the learners' languages, cultures and communities while providing them with the mathematical knowledge needed to survive and thrive in the dormant culture. This affords learners long life skills for real-life application.

The interpretation of water and electricity bills, bank statements, payslips, compound and simple interests, as well as foreign exchange, is done in almost all cultures in Zimbabwe. When these concepts are learned in the classroom through linking them to their real-life experiences, there is a better understanding and analysis of such concepts. Ethnomathematics is involved in everyday life activities which include building houses, exchanging money, buying and selling, weighing products and calculating proportions for a recipe involving numbers (Rosa \& Orey, 2011). Carraher et al. (1985) cited in Rosa and Orey (2011) reported that every day, out-of-school mathematics supports the learning of school mathematics. For instance, in consumer arithmetic, some mathematics concepts are developed outside the school systems without any specific instructions, because these concepts and procedures would be learned through social interactions in everyday activities such as commerce and the production of goods.

Some studies support the integration of ethnomathematics approaches into the teaching of various mathematics concepts and they show that these approaches improve learners' achievement in mathematics. In a quasi-experimental study conducted by Arishmendi-Pardi (2001) in Orange Coast College in Florida on intermediate algebra with two groups, one with a traditional approach and the other one with an ethnomathematics approach. The study was carried out with college learners, where researcher taught the both the experimental and the control groups. Data was collected using pre and post-tests only. The findings of the study showed a positive effect of an ethnomathematics approach on intermediate algebra achievement. Learners who were taught with an ethnomathematics approach outperformed those who were taught with the traditional approach.

In another experimental study conducted in Nigeria, Abiam et al. (2016) reported that ethnomathematics is a significant approach that improves meaningful understanding of concepts, increases retention and recall of concepts in geometry. The study involved primary school learners who wrote pre and post-test on geometry. The learners taught with the ethnomathematics approach had a higher retention rate in geometry than the learners taught with the traditional approach. The researchers concluded that the learners in the experimental group had developed operational communication and confidence in learning geometry.

Achor et al. (2009) in Nigeria carried out an experimental study to find out the usefulness of ethnomathematics approaches on learners' achievement and retention on the topic of locus. The study involved Senior Secondary School 2 (SS2) learners. SS2 is equivalent to grade 11. The learners who were taught with an ethnomathematics approach were involved in practical activities such as pegging farming land and roofing round huts. The other group of learners was taught using the traditional approach. Both groups of learners wrote the same pre and post-tests on the locus. The findings of the study showed that learners taught with an ethnomathematics approach had a higher mean achievement score as compared to their counterparts taught with the traditional approach. The learners taught with ethnomathematics approaches had higher achievement and retention as compared to those exposed to traditional approaches. The researchers concluded that the higher achievement and retention was due to the reason that learners taught with ethnomathematics were able to connect the cultural activities in their societies with the learning of locus. They pointed out the possibility of reducing the abstract nature of the teaching and learning of mathematics if ethnomathematics approaches were used. Despite the positive results in the studies above, some studies concluded that ethnomathematics approaches do not have any significant effect on the learners' achievement in mathematics. For instance, a study conducted by Kara and Togrol (2010) to develop instruction integrated with ethnomathematics as well as evaluate its effects on learners' achievement and their attitudes toward geometry. The findings of the results showed that there was no significant difference between the achievement levels of the control and the treatment group. Other reasons such as the examples and activities used during the teaching could account for the inconsistency in the findings. However, besides achievement, the findings of the same study showed positive effects on learners' attitudes towards mathematics.

Although studies have been carried, using tests as data gathering instruments that collect quantitative data only in Florida and Nigeria on the effectiveness of ethnomathematics approaches, there are no such similar studies in Zimbabwe. Therefore, this study attempts to give additional substance to the discussion through gathering both qualitative data from interviews and quantitative data from tests, given that the mathematics syllabus recommends the use of the learners' cultural, everyday life experiences and the immediate environment in the teaching of mathematics. The study sought to address whether ethnomathematics approaches would result in better achievement as compared to the traditional lecture approaches, defined in this study as the habitual methods of teaching mathematics since various researchers have associated the difficulty of learning certain mathematics topics with inappropriate teaching approaches (Harbor-Peters, 2001; Mashingaidze, 2012; Sunzuma \& Maharaj, 2019; Telima, 2011). The questions addressed in this study are:

1) What is the effect of using ethnomathematics and traditional lecture approach on learners' achievement in consumer arithmetic?

2) What are the teachers' views regarding the use of ethnomathematics approaches and the traditional lecture approaches in the teaching and learning of consumer arithmetic?

\section{METHODOLOGY}

\section{Design}

The study followed an embedded mixed-method approach involving an experimental study to compare the achievement of the learners in intact classes who had been exposed to ethnomathematics and traditional lecture approaches. An embedded mixed methods design incorporates both quantitative and qualitative data (Creswell, 2015). A Posttest-Only Control-Group Design 
where learners from the experimental group were taught using the ethnomathematics approach was used to collect quantitative data. According to Creswell (2015) the treatment is administered to the experimental group only and both groups are measured on the posttest. Qualitative data from the teachers' interviews were used to complement the quantitative data from the test. The basis for using an embedded mixed-method design was to gain a better understanding of the research problem (Creswell, 2015). The research questions under study required a research design that went beyond straightforward numbers in quantitative data or simple words in qualitative data hence an amalgamation of both quantitative and qualitative data in a single study that affords a more complete analysis of the research problems (Angell \& Townsend, 2011; Creswell, 2015; Creswell \& Plano Clark, 2011). According to Cohen et al. (2015) a research question cannot be answered sufficiently by drawing only on one method but requires data from both qualitative and quantitative methods for a complete understanding of the research problem.

\section{Instrument}

The instruments used in the study were a test for the learners which gathered quantitative data and an interview for the teachers which gathered qualitative data. Two tests were constructed by the researchers to measure learners' achievement in consumer arithmetic concepts. The researchers were guided by the mathematics syllabus in constructing the test items. The first test consists of six questions on profit, discount and hire purchase concepts (see Appendix A). The second test comprised of five questions on the compound and simple interest and balancing of a statement from companies and banks (see Appendix B). The tests were marked and the marks were expressed as percentages. The participating teachers were interviewed after the learners had written the two tests which were set by their teachers and the researchers. There were four interview questions on the methods the teachers were using to teach consumer arithmetic and on their experiences on the ethnomathematics approaches. The questions were: 1 . What are the teaching methods that you prefer most when teaching consumer arithmetic concepts? Explain the choice of your methods, 2. Explain the typical activities that you normally do when teaching consumer arithmetic concepts? 3. What have you learned/ gained from being involved in this project? 4. What do you think about the preparation time required for ethnomathematics approaches? The interviews were tape-recorded to allow replay during data analyses. On average each interview lasted 45 minutes.

\section{Validity and Reliability}

The test and interview schedule were piloted with one secondary school and his learners from a neighboring school to ensure the credibility and trustworthiness of the instruments. This was to ensure that the questions were clear and would provide answers to research questions. The test items and the interview items were face validated and content validated by an expert in mathematics education. Member checking, a quality control process that is used to improve accuracy, credibility and validity of data gathering instruments was also used in this study. The participants were asked to authenticate if the captured records were a true reflection of what took place during the interview. The participants confirmed that the information was accurate, which served as an assurance for legitimacy.

\section{Research Participants}

According to Merriam (2009) purposive sampling is used when the researcher intends to discover, understand, gain sight; therefore a sample from which the researchers could learn the most was selected. One government school was purposively sampled from the schools in Bindura district in Zimbabwe. The school enrolls learners from low to medium socioeconomic status. The selected school is close to a nearby township in the district and was selected with the assumption that both the teachers and learners were familiar with the place and the day-to-day consumer activities happening at the township. Two separate intact form two classes from the selected school were purposively selected to participate in the study from four classes. The selection of the form two classes was based on the fact that consumer arithmetic is taught at form two level. The two classes were selected on the basis that they had the learners with the best Grade 7 results (five and six units only) which are obtained after seven years of primary education. The learners were randomly assigned to those two classes, with each class having an equal number of learners with five and six points. This form of random assignment enabled the researchers to assume that the two classes were probabilistically equivalent in terms of academic performance, hence the pretest was not required (Trochim, 2006). The two intact classes were randomly assigned to the control and experimental groups. The experimental class consisted of 50 learners ( 28 girls, 22 boys), whilst the other class comprising of 40 (19 girls, 11 boys) made up the control class. The difference in numbers at the time of the study was due to dropouts and transfers. Two teachers who were responsible for teaching the two intact classes formed the sample of the teachers. The two teachers were qualified to teach consumer arithmetic concepts as both of them were Diploma in Science holders majoring in mathematics. The two teachers had a minimum of ten years teaching Ordinary level (' $O$ ' level) mathematics, which implies that they had gained substantial experience in teaching consumer arithmetic concepts.

\section{Research Procedure and Data Collection}

The two mathematics teachers from the selected school taught the learners. These teachers were trained by the researchers a week before commencing the study. The duration of training was three days, putting more emphasis on planning and implementing ethnomathematics approaches. The purpose of the training exercise was to acquaint the teachers with the topic to be taught, ethnomathematics approaches, the use of the lesson plans, the use of the tests and the overall conduct of the study. The teachers were also trained to teach both the control and the experimental groups.

The ethnomathematics approach as applied in the study involved visiting various places such as the banks, furniture shops and the market where there is the use of consumer arithmetic. The learners had an opportunity to look at electricity and water bills, bank statements, visit foreign exchange places. The visits were done during the lunch hours for four weeks, with the researchers, the teachers and the learners from the experimental group. After the exposure to various places where there is the 
Table 1. Summary of post-test descriptive and inferential statistics of the two tests

\begin{tabular}{|c|c|c|c|c|c|c|}
\hline \multicolumn{7}{|c|}{ Post-test statistics } \\
\hline Test & Treatment & $\mathbf{n}$ & Mean & Standard Deviation & F-value & p-value \\
\hline \multirow{3}{*}{ Test 1} & Experimental & 50 & 53.9 & 19.0 & 25.04 & $<0.0001$ \\
\hline & Control & 40 & 39.9 & 14.2 & & \\
\hline & Difference & & 14 & & & \\
\hline \multirow{3}{*}{ Test 2} & Experimental & 50 & 67.2 & 19.0 & 17.2 & $<0.0001$ \\
\hline & Control & 40 & 50.2 & 24.2 & & \\
\hline & Difference & & 17 & & & \\
\hline
\end{tabular}

use of consumer arithmetic, the teacher would then teach the learners using the ethnomathematics approach. The traditional lecture method involved teaching the learners without referring to how consumer arithmetic is applied in real-life situations such as in banks.

The teachers taught both the experimental group using ethnomathematics approaches and the control group using the traditional lecture approaches for four weeks. Consumer arithmetic concepts were divided into two such that half of the concepts were taught during the first two weeks and the other half in the last two weeks. The teacher who taught the experimental group during the first two weeks switched to the control class during the last two weeks and this also applied to the teacher who taught the control group during the first two weeks. Switching teachers halfway through made the groups more equivalent. It was important that the two teachers taught the two groups using the two approaches for comparison purposes. Each teacher taught ten ethnomathematics-based lessons and ten traditional-based lessons. To ensure that the teachers adhere to the instructional approaches and the lesson plan, they were closely monitored by the researchers. The researchers made sure that the teachers taught the same consumer arithmetic concepts to both groups at the stipulated equal length of time. For example, the concepts on hire purchase were taught to the two groups in 35 minutes using the ethnomathematics approach for the experimental group and using the traditional approach for the control group. The same concepts were taught to the two groups using different approaches. A total of twenty lessons were taught to each of the classes. At the end of every two weeks, a one hour test was written by both the experimental and control groups.

\section{Data Analysis}

Descriptive and inferential statistics to analyze the findings from the test. The interviews were transcribed and inductively analyzed using recitation to report the findings. The inductive analysis involves reading and re-reading the transcribed interviews. Responses were then classified into themes. For confidentiality purposes, the two participating teachers are referred to as Teacher $\mathrm{X}$ and Teacher $\mathrm{Y}$.

\section{FINDINGS AND DISCUSSION}

\section{Quantitative Data from the Post-test}

Table 1 shows a summary of the post-test descriptive and inferential statistics of two tests.

Results in Table 1 showed a significant difference between the mean achievement scores of those taught with ethnomathematics approach and those taught with the traditional lecture approach is significant at .05 alpha level. The experimental class performed significantly better in test $1(F=25.04, p<0,0001)$ and test $2(F=17.2, p<0,0001)$. The experimental class had a higher mean which might imply that learners were able to relate the topic of consumer arithmetic to their culture and experiences. This finding is in line with that of Achor et al. (2009). In summary, the use of an ethnomathematics approach was significantly more effective than the traditional lecture approach in improving learners' achievement in consumer arithmetic. The findings concur with earlier findings by Abiam et al. (2016), and Achor et al. (2009) who reported that learners perform better when taught using ethnomathematics approaches than the traditional lecture approach. The experimental group was taught in a practical way such as connecting the learners' everyday living to the mathematics they are taught in schools (Mogari, 2014). This is in line with D'Ambrosio's (2001) definition of ethnomathematics which states that it is a mathematics teaching method that builds on the learners" prior knowledge and the role played by their environment.

\section{Qualitative Data from the Interview}

Three themes merged in the analysis of the teachers' interview responses. The themes were classified as teachers' teaching practices, using out-of-school experiences as resources for teaching consumer arithmetic and connecting consumer arithmetic to the learners' cultural background and experiences.

\section{Teachers' existing instructional strategies}

The teachers were asked to describe the teaching methods that they use when teaching consumer arithmetic concepts and explain why they use such methods. Teacher $Y$ said:

I use the lecture method in all my lessons. The lecture method saves time as compared to ethnomathematics approaches that are time-consuming especially with activities that involve field trips. Time is wasted moving from one place to another, it is better to use that time to teach. Such trips are also expensive when it comes to transport issues. 
The findings showed that teacher $Y$ used the traditional approach only for all six lessons. On the other hand, out of the six lessons per week, teacher $\mathrm{X}$ used the traditional approach for five lessons and the ethnomathematical approach only for one lesson. Teacher $\mathrm{X}$ said:

I sometimes make use of ethnomathematics approaches once a week out of the six lessons, for the reason that learners would be able to generate their solutions for problems and stimulate their critical thinking skills and promote higher-order thinking abilities. If learners search for knowledge and solutions on their own it makes them motivated and self-reliant in real life.

From teacher Y's response, ethnomathematics approaches are viewed as time-consuming and in some cases expensive to visit places where consumer arithmetic activities are practiced. The finding that ethnomathematics approaches are time-consuming concurs with earlier findings by Sunzuma and Maharaj (2019). In such situations, the teachers resort to traditional approaches that might result in learners' failure to recognize the relevance of consumer arithmetic to their lives as well as poor achievement in examinations and tests. Teacher Y's response showed that mathematics concepts that the learners might have developed from their cultural backgrounds were not taken into consideration when teaching. The use of ethnomathematics approaches was limited to only one lesson per six lessons as indicated by Teacher X. From the above remarks, the two teachers mainly make use of the traditional approaches that do not take into account the mathematics knowledge that learners might develop out of school. The finding is in line with earlier findings by Mogari (2014) and Sunzuma and Maharaj (2019) who reported that ethnomathematics approaches were partially or not being integrated into the teaching and learning of mathematics. According to Sunzuma and Maharaj (2019), the overreliance on the traditional approaches of teaching is one of the factors that contributes to learners' poor performance in mathematics.

The teachers were also asked to explain the typical activities they embark on when teaching consumer arithmetic concepts. Teacher $\mathrm{X}$ gave the following remarks:

I usually start by explaining to the learners what the lesson is about using the chalkboard. I introduce the concepts using examples from the textbooks. After teaching, I will give individual work in form of exercises to check on how much they would have understood.

Teacher Y said:

In most cases I use the question and answer technique, I ask a question, giving instructions and telling them what they should do during the lesson, and explain to them what the topic is all about. I also demonstrate how to get the answers on the chalkboard. After the lesson, they copy homework questions from the chalkboard.

Teacher $X$ uses the chalkboard and textbook examples when teaching consumer arithmetic concepts. The teachers also assign individual work that might assist in all learners participating. Teacher $Y$ makes use of the question and answer technique to facilitate learners' understanding. From the two teachers' remarks, it is clear that none of them refer to the learners' cultural experiences and out-of-school experiences, including Teacher $X$ who had indicated earlier that he uses ethnomathematics approaches in one out the six lessons when teaching. In spite of the possible benefits of integrating ethnomathematics approaches into the teaching and learning of consumer arithmetic, the findings revealed that none of the two teachers use such an approach when teaching. An analysis of the teachers' existing practices showed that there is a limited link of consumer arithmetic to the learners' everyday lives and culture. The findings concur with researchers (Madudise, 2015; Mogari, 2014; Sunzuma \& Maharaj, 2019) who reported that ethnomathematics approaches were hardly used in the classroom. Research has shown that learners coming from different cultural backgrounds might succeed academically if the teaching and learning approaches are responsive to their home culture (Madudise, 2015).

Using out of school experiences as resources for teaching consumer arithmetic

The teachers were asked what they learned from participating in this study. Teacher $Y$ said:

I have learned that teaching is not confined to the four walls of the classroom. I can now use resources from outside the classroom to plan and teach not only consumer arithmetic but other mathematics topics too.

Teacher $\mathrm{X}$ said:

I had come to realize that learners can be given a task that requires them to visit some places such as banks or other places in order for them to research more on mathematical concepts.

When describing what they have learned teachers also pointed to how the learners had benefited from the ethnomathematics approach. Teacher $Y$ claimed that he had seen a great change in learners' attitudes towards consumer arithmetic. Teacher $Y$ said:

During the teaching and learning period, learners were motivated, were actively involved and were even answering given tasks on their own. I got the impression that the lessons were interesting as learners were participating very, very well and the methods help to eliminate boredom in learners.

Teacher $\mathrm{X}$ said: 
I think visiting the places such as banks made the whole teaching and learning process funny and interesting. The more they were interested in the activities and visits the more they learn and approaching mathematics from this stance has more impact on the learners than the traditional approach.

The teachers' remarks showed that they valued connecting the learners' cultural backgrounds and their everyday life to the teaching and learning of mathematics. To them, the use of ethnomathematics approaches might help learners learn more as well as making them interested in learning the concepts. Benefits such as motivation and interest, active involvement and being able to link school concepts on consumer arithmetic to real-life situations resulted from the use of ethnomathematics approaches. These findings are consistent with Madudise's (2015) observation that the use of ethnomathematics approaches has several benefits including motivation, interesting and active participation.

\section{Connecting consumer arithmetic to the learners' cultural background and experiences}

The teachers were also asked what they think about the time required to prepare for an ethnomathematics lesson. Teacher $Y$ said:

I think it is important to link the mathematics concepts with what is found in the learners' cultural environments. I realized that learners understand better when they are taught using the resources from their environments.

Teacher Y said:

If we are to teach using what we do every day in our homes or lives, teaching and understanding improve, I mean teaching becomes very easy and this is important for the learners. I think we need to use more of the learners' cultural backgrounds and experiences when teaching.

The above statements by teachers showed the importance of connecting the teaching of consumer arithmetic to the learners' lives that may lead to a deeper understanding of the concepts. The integration of learners' background activities as well as their prior knowledge in the teaching and learning of consumer arithmetic makes teaching easier and enhances the learners' understanding of consumer arithmetic concepts and retention. The findings are in line with the view held by Madusise (2015), who pointed out that ethnomathematics approaches improve learners' understanding and retention of mathematics concepts.

\section{CONCLUSION}

The findings revealed that learners' achievement in consumer arithmetic tests was dependent on the teaching approach that was used. The learners that were taught with the ethnomathematics approaches did very well as compared to those who were taught with the traditional approaches. The analysis from the teachers' existing practices showed that the use traditional lecture approach was dominant in the teaching and learning of consumer arithmetic, which contributes to poor performance and leading to learners' boredom as alluded to by Sunzuma and Maharaj (2019). However, teachers valued the use of ethnomathematics approaches in the teaching of not only consumer arithmetic but also in other mathematics topics as they make learners motivated, actively involved and interested in learning mathematics concepts. Teachers also reported that ethnomathematics approaches improve learners' understanding and retention of arithmetic concepts. Therefore, it is recommended that the teaching and learning of mathematics be connected to the learners' cultural backgrounds and experiences through workshops for in-service teachers and training in mathematics methods courses in teacher training institutions for pre-service teachers.

The study was limited to one school in Zimbabwe, involving two classes and two teachers only, hence the findings may not be transferable to other schools in the country. Research could be carried out on a large scale using the same topic or other mathematics topics.

Author contributions: All authors have sufficiently contributed to the study, and agreed with the results and conclusions.

Funding: No funding source is reported for this study.

Declaration of interest: No conflict of interest is declared by authors.

\section{REFERENCES}

Abiam, P. O., Abonyi, O. S., Ugama, J. O., \& Okafor, G. (2016). Effects of ethnomathematics-based instructional approach on primary school pupils' achievement in geometry. Journal of Scientific Research \& Reports, 9(2), 1-15. https://doi.org/10.9734/JSRR/2016/19079

Achor, E. E., Imoko, B. I., \& Uloko, E. S. (2009). Effects of ethnomathematics teaching approach on senior secondary students' achievement and retention in locus. Educational Research and Review, 4(8), 385-390. http://www.academicjournals.org/ERR

Arishmendi-Pardi, E. J. (2001). Comparison of the final grades of students in intermediate algebra taught with and without and ethnomathematical pedagogy [Paper presentation]. The Center of Diversity in Teaching and Learning in Higher Education, Miami, FL, USA.

Chiwiye, T. (2013). Assessment of mathematics and science subjects in Zimbabwe: ZIMSEC Perspective, ZIMSEC.

Creswell, J. W. (2015). A concise introduction to mixed methods research. Sage Publications. 
D'Ambrosio, U. (2001). What is Ethnomathematics and how can it help children in schools? Teaching Children Mathematics, 7(6), 308-310. https://doi.org/10.5951/TCM.7.6.0308

Harbor-Peters, V.F.A. (2001). Unmasking some aversive aspects of school mathematics and strategies for averting them [Inaugural lecture]. The University of Nigeria, Enugu, Nigeria.

Kara, M., \& Togrol, A. Y. (2010). Effects of instructional design integrated with ethnomathematics: Attitudes and achievement. In K. Gomez, L. Lyons, \& J. Radinsky, (Eds.), Learning in the Disciplines: Proceedings of the $9^{\text {th }}$ International Conference of the Learning Sciences (pp. 730-735). International Society of the Learning Sciences.

Kurumeh, M. S. C. (2004). Effects of ethnomathematics teaching approach on students' achievement and interest in geometry and mensuration [Unpublished doctoral dissertation]. University of Nigeria.

Madusise, S. (2010). Exploring the potential of using basket and mat weaving in the teaching and learning of mathematics [Occasional Paper]. The Centre for Advanced Studies of African Society. Cape Town, South Africa.

Madusise, S., \& Mwakapenda, W. (2014). Using school mathematics to understand cultural activities: How far can we go? Mediterranean Journal of Social Sciences, 5(3), 146-157. https://doi.org/10.5901/mjss.2014.v5n3p146

Mashingaidze, S. (2012). The teaching of geometric (isometric) transformations at secondary school level: What approach to use and why? Asian Social Science, 8(15), 197-210. https://doi.org/10.5539/ass.v8n15p197

Merriam, S. B. (2009). Qualitative Research: A guide to design and implementation. Jossey-Bass Publishers.

Mogari, D. (2014). An in-service programme for introducing an ethnomathematical approach to mathematics teachers. Africa Education Review, 11(3), 348-364. https://doi.org/10.1080/18146627.2014.934992

Rosa, M., \& Orey, D. (2009). Symmetrical freedom quilts: the ethnomathematics of ways of communication, liberation, and art. Revista Latinoamericana de Etnomatemática, 2(2), 52-75. http://www.etnomatematica.org/v2-n2-agosto2009/rosa-orey.pdf

Rosa, M., \& Orey, D. (2013). Culturally relevant pedagogy as an ethnomathematical approach. Journal of Mathematics and Culture, $7(1), 74-97$.

Rosa, M., \& Orey, D. C. (2007). Cultural assertions and challenges towards pedagogical action of an ethnomathematics program. For the Learning of Mathematics, 27(1), 10-16. https://flm-journal.org/Articles/7E5EFFA4B24CB97110973C060200F3.pdf

Rosa, M., \& Orey, D. C. (2011). Ethnomathematics: The cultural aspects of mathematics. Revista Latinoamericana de Ethnomatica, 4(2), 32-54.

Sunzuma, G., \& Maharaj, A. (2019). Teacher-related Challenges Affecting the Integration of Ethnomathematics Approaches into the Teaching of Geometry. EURASIA Journal of Mathematics, Science and Technology Education, 15(9), 1-15. https://doi.org/10.29333/ejmste/108457

Sunzuma, G., Ndemo, Z., Zinyeka, G., \& Zezekwa, N. (2012). The challenges of implementing student centred instruction in the teaching and learning of secondary school mathematics in a selected district in Zimbabwe. International Journal of Current Research, 4(5), 145-155.

Telima, A. (2011). Problems of teaching and learning geometry in secondary schools in Rivers State, Nigeria. International Journal of Emerging Science, 1(2), 143-152. http://hdl.handle.net/1893/26189

Umbara, U., Wahyudin, W., \& Prabawanto, S. (2021). How to predict good days in farming: ethnomathematics study with an ethnomodelling approach. Journal of Research and Advances in Mathematics Education, 6(1), 71-85. https://doi.org/10.23917/jramathedu.v6i1.12065

Weldeana, H. N., (2016). Ethnomathematics in Ethiopia: Futile or Fertile for Mathematics Education? Momona Ethiopian Journal of Science 8(2), 146-167. https://doi.org/10.4314/mejs.v8i2.4

Zimbabwe School Examination Council. (2015). Ordinary level mathematics syllabus. Harare.

Zimbabwe School Examination Council. (2016). Ordinary level mathematics examiners' Report. (Report No. 4008-01.N16). 